plastic/myeloproliferative neoplasms. Blood 2014;123:2645-51.

10. Patnaik MM, Barraco D, Lasho TL, et al. Targeted next generation sequencing and identification of risk factors in World Health Organization defined atypical chronic myeloid leukemia. Am J Hematol 2017;92:542-8.

11. Hernández JM, del Cañizo MC, Cuneo A, et al. Clinical, hematological and cytogenetic characteristics of atypical chronic myeloid leukemia. Ann Oncol 2000;11:441-4.

12. Martiat $\mathrm{P}$, Michaux JL, Rodhain J. Philadelphia-negative ( $\mathrm{Ph}-)$ chronic myeloid leukemia (CML): comparison with $\mathrm{Ph}+\mathrm{CML}$ and chronic myelomonocytic leukemia. The Groupe Français de Cytogénétique Hématologique. Blood 1991;78:205-11.

13. Koldehoff M, Steckel NK, Hegerfeldt Y, Ditschkowski M, Beelen DW, Elmaagacli AH. Clinical course and molecular features in 21 patients with atypical chronic myeloid leukemia. Int J Lab Hematol 2012;34:e3-5.

14. Mittal P, Saliba RM, Giralt SA, et al. Allogeneic transplantation: a therapeutic option for myelofibrosis, chronic myelomonocytic leukemia and Philadelphia-negative/BCR-ABL-negative chronic myelogenous leukemia. Bone Marrow Transplant 2004;33: 1005-9.

15. Dhakal P, Gundabolu K, Amador C, Rayamajhi S, Bhatt VR. Atypical chronic myeloid leukemia: a rare entity with management challenges. Future Oncol 2018;14:177-85.

\section{Successful treatment of non-lgM lymphoplasmacytic lymphoma by bortezomib-containing regimen: case reports and review of literature}

TO THE EDITOR: Lymphoplasmacytic lymphoma (LPL) with non-immunoglobulin $\mathrm{M}(\operatorname{IgM})$ paraproteinemia is a rare subtype of LPL [1]. Furthermore, the clinicopathological features and appropriate treatment regimen for non-IgM LPL have not been clarified. Non-IgM LPL reportedly has a higher rate of extramedullary involvement and poorer overall survival than IgM LPL-Waldenström macroglobuli- nemia (WM) [2]. Herein, we report two cases of successful treatment of non-IgM LPL using bortezomib (Bor)-containing regimen, in addition to a literature review.

\section{Case 1}

A 71-year-old man was referred to our hospital with fever and abdominal pain for one month. The laboratory findings were as follows: white blood cells (WBC), $6.6 \times 10^{9} / \mathrm{L}$; hemoglobin $(\mathrm{Hb}), 9.8 \mathrm{~g} / \mathrm{dL}$; platelet $(\mathrm{PLT}), 500 \times 10^{9} / \mathrm{L}$; total protein (TP), $7.5 \mathrm{~g} / \mathrm{dL}$; albumin (Alb), $2.8 \mathrm{~g} / \mathrm{dL}$; lactate dehydrogenase (LDH), $195 \mathrm{IU} / \mathrm{L}$; compensated Ca, $9.9 \mathrm{mg} / \mathrm{dL}$; C-reactive protein (CRP), $6.28 \mathrm{mg} / \mathrm{dL} ; \mathrm{IgG}, 2363 \mathrm{mg} / \mathrm{dL}$ (normal range, 861-1,747 mg/dL); IgA, $147 \mathrm{mg} / \mathrm{dL}$; and IgM, $41 \mathrm{mg} / \mathrm{dL}$. Serum protein electrophoresis demonstrated an $\mathrm{M}$-spike in the gamma fraction, and the serum immunofixation test revealed monoclonal bands of IgG and kappa. A soft tissue mass in the mesenteric lymph nodes was observed on computed tomography (CT) (Fig. 1A). Bone marrow (BM) aspiration revealed abnormal increases in atypical small lymphocytes, lymphoplasmacytes, and plasmacytes. The biopsy specimen of the BM exhibited diffuse infiltration of atypical small lymphocytes, lymphoplasmacytes, and plasmacytes (Fig. 2A). On immunohistochemical staining, the atypical lymphoplasmacytes and plasmacytes were positive for CD138 (Fig. 2B); however, CD79a, IgG-kappa, and CD20 expression was weak (Fig. 2C). Conventional cytogenetic analysis of the BM aspirate demonstrated a normal karyotype, and fluorescence in-situ hybridization (FISH) analyses for translocations involving immunoglobulin heavy chain, including IgH-BCL1, chromosome (chr) 13q deletion (del), and chr 6q del, were negative. Thus, the patient was diagnosed with LPL with IgG-kappa M protein, accampanying B symptoms and a mesenteric mass. The patient was categorized as having an intermediate risk according to the international prognostic scoring system for WM [3]. He was treated using BDR therapy [4], which was modified for the Japanese health insurance system: one cycle of subcutaneous injection of Bor $\left(1.3 \mathrm{mg} / \mathrm{m}^{2}\right)$; oral dexamethasone (Dex, $20 \mathrm{mg}$ ) on days 1, 2, 4, 5, 8, 9, 11, and 12; and rituximab $\left(\mathrm{R}, 375 \mathrm{mg} / \mathrm{m}^{2}\right)$ on day 11 . For induction therapy, four cycles were repeated every three weeks, followed by four more cycles for maintenance therapy three months
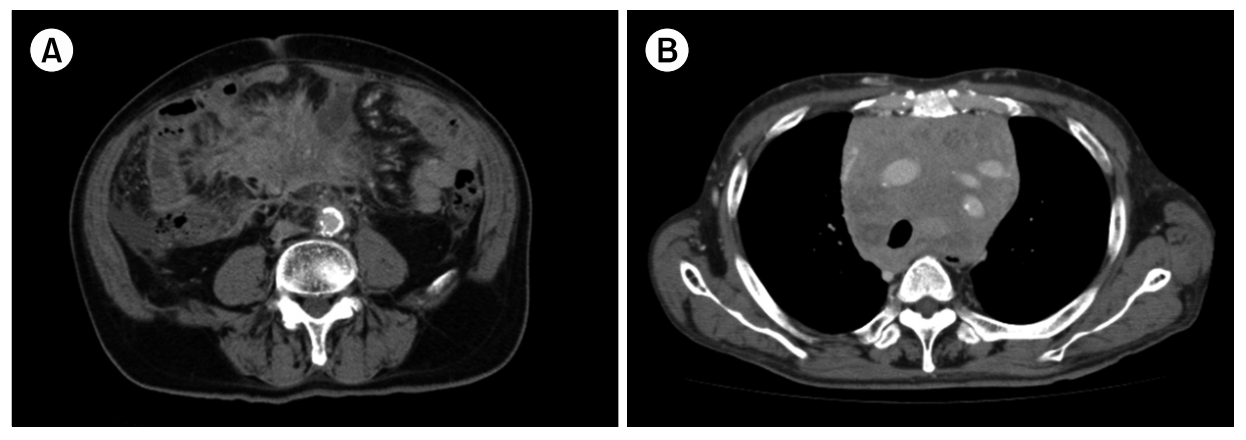

Fig. 1. Computed tomography at diagnosis. (A) A soft tissue mass in the mesenteric lymph nodes in Case 1. (B) A bulky mass in the mediastinum in Case 2. 

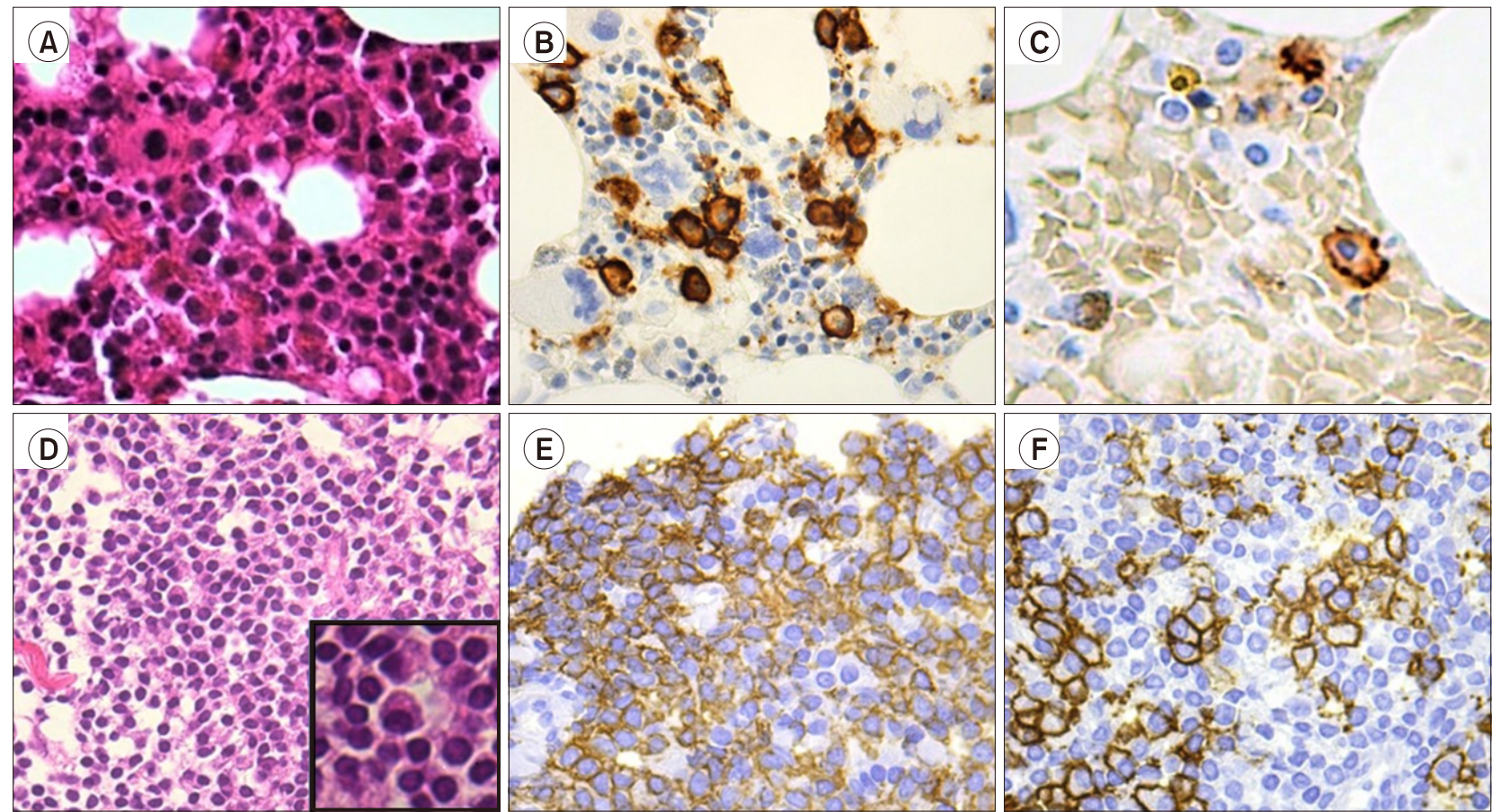

Fig. 2. (A-C) Neoplastic cells in the bone marrow in Case 1. (A) Hematoxylin and eosin staining: diffused invasion of the neoplastic cells was observed in the bone marrow biopsy specimen (original magnification $\times 400$ ). (B) Staining with CD138: The cytoplasm of the neoplastic lymphoplasmacytes and plasmacytes was strongly positive for CD138 $(\times 400)$. (C) Staining with CD20: The cytoplasm of the neoplastic small lymphocytes and lymphoplasmacytic cells were strongly positive for CD20 $(\times 630)$. (D-F) The neoplastic cells of the mediastinum tumor mass in Case 2. (D) Hematoxylin and eosin staining: Neoplastic lymphocytes, lymphoplasmacytes, and plasmacytes were noted in the mediastinum tumor specimen $(\times 400)$. (E) Staining with CD20: The cytoplasm of the neoplastic lymphocytes was strongly positive for CD20 ( $\times 400)$. (F) Staining with CD138: The cytoplasm of the neoplastic lymphoplasmacytes and plasmacytes was strongly positive for CD138 $(\times 400)$.

Table 1. Treatment schedule for bortezomib, dexamethasone, and rituximab.

\begin{tabular}{|c|c|c|c|c|c|c|c|c|}
\hline Day & 1 & 2 & 4 & 5 & 8 & 9 & 11 & 12 \\
\hline $\begin{array}{l}\text { Bortezomib (SC) }\left(1.3 \mathrm{mg} / \mathrm{m}^{2}\right) \\
\text { Dexamethasone (PO) }(20 \mathrm{mg}) \\
\text { Rituximab DIV }\left(375 \mathrm{mg} / \mathrm{m}^{2}\right)\end{array}$ & $\begin{array}{l}\downarrow \\
0\end{array}$ & 0 & $\begin{array}{l}\downarrow \\
0\end{array}$ & 0 & $\begin{array}{l}\downarrow \\
0\end{array}$ & 0 & $\begin{array}{l}\downarrow \\
\bullet \\
\downarrow\end{array}$ & • \\
\hline
\end{tabular}

For induction therapy, 4 cycles were repeated every 3 weeks, followed by 4 more cycles for maintenance therapy every 3 months. Abbreviations: DIV, intravenous drip; PO, per os; SC, subcutaneous injection.

apart (Table 1). In this case, $\mathrm{R}$ was omitted because of the weak expression of CD20 in the neoplastic cells. After the first cycle of $\mathrm{BD}(\mathrm{R})$ therapy, fever and abdominal pain promptly disappeared. After four cycles of $\mathrm{BD}(\mathrm{R})$, the serum IgG level decreased to within the normal range, serum M-protein became undetectable by the immunofixation test, and the soft tissue mass was not visible on CT. Thus, the patient achieved a complete response (CR) according to the 6th International Workshop of WM response criteria [5], and the CR has been maintained for six months.

\section{Case 2}

A 59-year-old man was refered to our hospital with anemia in 2006. The laboratory findings were as follows: WBC,
$4.0 \times 10^{9} / \mathrm{L} ; \mathrm{Hb}, 7.9 \mathrm{~g} / \mathrm{dL} ; \mathrm{PLT}, 330 \times 10^{9} / \mathrm{L} ; \mathrm{TP}, 8.5 \mathrm{~g} / \mathrm{dL} ; \mathrm{Alb}$, $3.2 \mathrm{~g} / \mathrm{dL}$; compensated $\mathrm{Ca}, 8.9 \mathrm{mg} / \mathrm{dL} ; \mathrm{IgG}, 4,135 \mathrm{mg} / \mathrm{dL}$; $\mathrm{IgA}, 55 \mathrm{mg} / \mathrm{dL}$; IgM, $42 \mathrm{mg} / \mathrm{dL}$; and beta 2-microglobulin, $5.1 \mathrm{mg} / \mathrm{L}$. Serum creatinine level was within the normal range, and proteinuria was not recognized. The serum protein electrophoresis showed an M-peak in the gamma fraction, although serum immunofixation test was not performed. The BM aspirate showed myeloma at that time; hence, he was initially diagnosed with symptomatic IgG myeloma. He was treated with two cycles of VAD therapy [28 days cycles of vincristine $(0.4 \mathrm{mg} / \mathrm{kg})$ with doxorubisin $\left(9 \mathrm{mg} / \mathrm{m}^{2}\right)$ by continuous intravenous infusion for 4 days, and dexamethasone $(40 \mathrm{mg} / \mathrm{kg}$ ) by intravenous infusion for 4 days] as an induction treatment, by which he achieved 
partial response. The patient had his first recurrence in 2009 and received BD therapy consisting of Bor and Dex [6] and achieved a very good partial response. In 2014, enlargement of the mediasinum without any symptoms was noted on a chest X-ray. The CT showed a mediastinal mass (Fig. 1B), slight enlargement of the post-peritoneal lymph nodes, and moderate splenomegaly. The biopsied specimen obtained from the mediastinal mass exhibited diffused infiltration of small- to medium-sized atypical lymphocytes with plasma cell differentiation (Fig. 2D). On immunohistochemical staining, the atypical lymphocytes were positive for CD20 (Fig. 2E), whereas atypical lymphoplasmacytes and plasmacytes were positive for CD138 (Fig. 2F). The serum immunofixation test demonstrated dual monoclonal bands of IgG-kappa and IgG-lambda. BM aspirate revealed diffuse infiltration of small lymphocytes, lymphoplasmacytes, and plasmacytes. G-banding of the BM aspirate resulted in 46 and XY. FISH analyses for IgH-BCL1, chr 13q del, and chr 6q del were negative. MYD88 L265P mutation was also negative. Furthermore, reconfirmation of BM aspirate obtained in 2006 revealed that the neoplastic cells were composed of atypical small lymphocytes, lymphoplasmacytes, and plasmacytes. Therefore, the precise diagnosis was revised from $\operatorname{IgG}$ myeloma to IgG LPL after re-evaluation. After local radiation therapy (36 Gy/17 Fr), the mediastinal tumor disappeared, and the patient had no symptoms at that time. The patient was followed under close observation without administering any systemic chemotherapy. He has not received chemotherapy for 10 years after BD therapy and is alive 13 years after the initial diagnosis.

\section{Discussion}

LPL is a neoplasm of the small B lymphocytes, lymphoplasmacytes, and plasmacytes involving the BM, lymph nodes, and the spleen. Conversely, WM is defined as LPL with $\mathrm{BM}$ involvement and IgM monoclonal gammopathy $[1,7]$. Recently, many cytogenetic and molecular analyses regarding the pathogenesis of LPL/WM have been reported. Chr 6q del was found in approximately 30-50\% and was reported to be one of the poor prognostic factors [8]. MYD88 L265P mutation was noted in approximately $90 \%$ of WM cases, and the mutation is widely accepted as the major mechanism for oncogenesis [9]. Conversely, $<5 \%$ of LPL cases have IgG, IgA, light chain, or no paraproteins. Due to its rarity, reports on clinicopathological features and treatment outcomes of non-IgM LPL are limited [2, 10-13].

More patients with non-IgM LPL reportedly exhibited extramedullary involvement than those with IgM LPL/WM [2]. Cao et al. [10] at MD Anderson Cancer Center (MDACC) reported the clinicopathological features of 17 patients with non-IgM LPL as compared to those of patients with IgM LPL/WM. They found that non-IgM LPL had a high rate of extramedullary involvement (52.9\%), including the kidneys, nasopharynx, dura, and central nervous system. Furthermore, they reported that the MYD 88 mutation was less common (40\%), and no notable differences in the pathological features were found between non-IgM LPL and IgM LPL/WM [10]. King et al. at the Mayo clinic reported that 10/23 (43\%) patients with non-IgM LPL had the MYD88 mutation, but there was no association between $M Y D 88$ status and morphological or phenotypical features in BM [11]. Thus, non-IgM LPL has a high rate of extramedullary invasion, low incidence of $M Y D 88$ mutation, and no notable pathological features compared with IgM LPL/WM. Focusing on cytogenetic aberrations, only these three studies have performed conventional cytogenetic analyses, and FISH analysis was not fully investigated; therefore, the incidence of chr $6 \mathrm{q}$ del was not clarified. The summary of the clinicopathological features in non-IgM LPL is shown in Table 2.

Regarding the treatment outcomes, the Asan Medical Center and MDACC groups reported that non-IgM LPL had poorer survival than IgM LPL/WM $[2,10]$. The Asan Medical Center group reported a median progression-free survival (PFS) and overall survival (OS) of 5.8 and 10 months, respectively [2]. According to the MDACC group, the 1-year mortality rate was $23.5 \%$ for non-IgM LPL, whereas that for IgM LPL/WM was 2.2\% [10]. Recently, treatments for IgM LPL/WM have markedly changed because many therapeutic agents have been developed $[14,15]$. Olszewski et al. reported 681 patients aged $\geq 65$ years for whom the first-line R-based therapy was initiated from 2008 to 2014 in the US [14]. Of them, 58\% received $\mathrm{R}$ alone, $22 \%$ received chemo-immunotherapy, $11 \%$ received a Bor-containing regimen, and $9 \%$ received a bendamustine (Benda)-containing regimen. They also noted that the proportion of Bor- or Benda-containing regimens significantly increased between 2008 and 2014, although there was no significant difference in the OS between immune-chemotherapy with classical agents and Bor- or Benda-containing regimens. A recent report from the Bing Center for WM retrospective analysis in the US has shown a similar response and long-term survival with Bor- or Benda-containing regimens, although the toxicity profile was different. Bor-containing regimen could induce neuropathy, while Benda-regimen could be associated with a risk of secondary leukemia; therefore, Bor-containing regimen is preferred in relatively younger patients [16].

In our two cases of non-IgM LPL, long-term survival was achieved using a Bor-containing regimen. In Asan Medical Center, one case was treated with a Bor-containing regimen and one another case was treated with a Benda-containing regimen out of 8 reported cases. Conversely, 1/17 cases at the MDACC received a Bor-containing regimen as an initial treatment (Table 2). The patients were alive during the study period. Recently, Varettoni et al. conducted a multicenter retrospective study with 45 patients with non-IgM LPL [12]. They reported that 35/45 patients (78\%) received a therapeutic intervention, and $26 \%$ received a Benda-containing regimen as the initial therapy. The 5-year PFS after first-line treatment was 55\%, whereas the OS 
Table 2. Summary of the clinicopathological features non-IgM lymphoplasmacytic lymphoma.

\begin{tabular}{|c|c|c|c|c|c|c|c|c|c|}
\hline $\begin{array}{l}\text { Author } \\
\text { (Ref No.) }\end{array}$ & Country & $\mathrm{N}$ & $\begin{array}{l}\text { Isotype } \\
\text { (IgG/A } \\
\text { other) }\end{array}$ & $\begin{array}{c}\text { Sex } \\
(\mathrm{M} / \mathrm{F})\end{array}$ & $\begin{array}{c}\text { Med age } \\
(y r)\end{array}$ & $\begin{array}{l}\text { Extramedullary } \\
\text { involvement } \\
\text { (\%) }\end{array}$ & $\begin{array}{l}\text { MYD88 } \\
\text { mutation } \\
(\%)\end{array}$ & Regimen & Survival \\
\hline $\begin{array}{l}\text { Kang et al. } \\
{[2]}\end{array}$ & Korea & 8 & $5 / 1 / 2$ & $7 / 1$ & $65.5(58-69)$ & $7(87.5 \%)$ & NA & $\begin{array}{l}\text { CHOP-like }(\mathrm{N}=3) \\
\text { Purine analog }(\mathrm{N}=1) \\
\text { Bortezomib }(\mathrm{N}=1) \\
\text { Benda }+\mathrm{R}(\mathrm{N}=1) \\
\text { Observation }(\mathrm{N}=1) \\
\text { Died before treatment }(\mathrm{N}=1)\end{array}$ & $\begin{array}{l}\text { Med PFS: } 5.8 \mathrm{mo} \\
\text { Med OS: } 10 \mathrm{mo}\end{array}$ \\
\hline $\begin{array}{l}\text { Cao et al. } \\
\text { [10] }\end{array}$ & U.S. & 17 & $9 / 8 / 0$ & $9 / 8$ & $63(46-80)$ & $9(52.9 \%)$ & 6/15 (40\%) & $\begin{array}{l}\text { CHOP-like } \pm R(N=5) \\
\text { Purine analog } \pm R(N=4) \\
\text { Bortezomib } \pm R(N=1) \\
R \text { alone }(N=1) \\
\text { IFN }(N=1) \\
\text { Observation }(N=3) \\
\text { Other }(N=2)\end{array}$ & $\begin{array}{l}5 \text { yr-OS: } 67 \% \\
10 \text { yr-OS: } 56 \%\end{array}$ \\
\hline $\begin{array}{l}\text { King et al. } \\
\text { [11] }\end{array}$ & U.S. & 23 & $21 / 2 / 0$ & $17 / 6$ & $70(46-86)$ & NA & 10/23 (43\%) & $\begin{array}{l}\text { CHOP-like } \pm R(N=7) \\
\text { Bortezomib } \pm R(N=3) \\
\text { Benda } \pm R(N=5) \\
R \text { alone }(N=1) \\
\text { Melphalan }(N=1) \\
\text { IMIDs }(\mathrm{N}=2) \\
\text { Observation }(N=4)\end{array}$ & NA \\
\hline $\begin{array}{l}\text { Varettoni } \\
\text { et al. [12] }\end{array}$ & Italy & 45 & $22 / 7 / 16$ & $19 / 26$ & $65.6(24.9-82.6)$ & $34(76 \%)$ & 6/34 (18\%) & $\begin{array}{l}\text { Alkylating agent } \pm R(N=12,34 \%) \\
C H O P-l i k e \pm R(N=11,31 \%) \\
\text { Benda } \pm R(N=9,26 \%) \\
\text { Purine analog } \pm R(N=2,6 \%)\end{array}$ & $\begin{array}{l}5 \text { yr-PFS: } 55 \% \\
5 \text { yr-OS: } 81 \%\end{array}$ \\
\hline $\begin{array}{l}\text { Itchaki } \\
\text { et al. [13] }\end{array}$ & U.S. & 31 & $20 / 5 / 6$ & $11 / 20$ & $63(37-83)$ & NA & 10/14 (71\%) & $\begin{array}{l}\text { Anti-CD20 antibody }(90 \%) \\
\text { Alkylating agent } \pm \mathrm{R}(48 \%) \\
\text { Purine analog } \pm \mathrm{R}(33 \%) \\
\text { Benda } \pm \mathrm{R}(38 \%) \\
\text { Proteasome inhibitor }(24 \%) \\
\text { IMIDs (14\%) }\end{array}$ & $\begin{array}{l}5 \text { yr-OS: } 90 \% \\
10 \text { yr-OS: } 81 \%\end{array}$ \\
\hline
\end{tabular}

Abbreviations: Benda, bendamustine; $\mathrm{CHOP}$, regimen of cyclophosphamide, doxorubicin, vincristine, and prednisolone; IFN, interferon $\alpha$; IMIDs, immunomodulatory drugs; NA, not applicable; OS, overall survival; PFS, progression-free survival; R, rituximab.

was $81 \%$ at 5 years. Furthermore, no difference was observed in PFS or OS between non-IgM LPL and IgM LPL/WM. Itchaki et al. analyzed 31 non-IgM LPL patients [13] who received a median of three lines of therapy including anti-CD20 monoclonal antibodies (90\% of patients), alkylating agents (48\%), Benda (38\%), purine analogues (33\%), and proteasome inhibitors including Bor $(24 \%)$ with a 5-year and 10 -year OS of $90 \%$ and $81 \%$, respectively. Considering these two recent reports, treatment regimens containing Bor might affect the favorable outcome in non-IgM LPL.

In conclusion, non-IgM LPL commonly has an extramedullary mass and a low incidence of $M Y D 88$ mutation due to the heterogeneous disease entity. Regarding treatment outcomes, Bor-containing regimens may lead to a favorable outcome than classical immuno-chemotherapy in non-IgM LPL. However, further studies are warranted.

Kenichi Ito', Risa Nishiyama ${ }^{1}$, Kazuhiko Hirano ${ }^{2}$, Kazuaki Yamada ${ }^{2}$, Naohiro Sekiguchi ${ }^{1,3}$

${ }^{1}$ Hematology Division, ${ }^{2}$ Laboratory and Pathology Division, ${ }^{3}$ Clinical Research Division, National Hospital Organization
Disaster Medical Center, Tokyo, Japan

Correspondence to: Naohiro Sekiguchi Hematology Division, National Hospital Organization Disaster Medical Center, 3256 Midori-cho, Tachikawa, Tokyo 190-0014, Japan

E-mail: nao26nao26@gmail.com

Received on Mar. 29, 2019; Revised on Jun. 22, 2019; Accepted on Aug. 7, 2019 https://doi.org/10.5045/br.2019.54.3.236

\section{Authors' Disclosures of Potential Conflicts of Interest}

No potential conflicts of interest relevant to this article were reported.

\section{REFERENCES}

1. Swerdlow SH, Cook JR, Sohani AR, et al. Lymphoplasmacytic lymphoma. In: Swerdlow SH, Campo E, Harris NL, et al, eds. World health organization classification of tumour of hematopoietic and lymphoid tissues. Lyon, France: IARC Press, 2017:232-5.

2. Kang J, Hong JY, Suh C. Clinical features and survival outcomes 
of patients with lymphoplasmacytic lymphoma, including non-IgM type, in Korea: a single-center experience. Blood Res 2018;53:189-97.

3. Morel P, Duhamel A, Gobbi P, et al. International prognostic scoring system for Waldenstrom macroglobulinemia. Blood 2009;113:4163-70.

4. Treon SP, Ioakimidis L, Soumerai JD, et al. Primary therapy of Waldenström macroglobulinemia with bortezomib, dexamethasone, and rituximab: WMCTG clinical trial 05-180. J Clin Oncol 2009;27:3830-5.

5. Treon SP, Merlini G, Morra E, Patterson CJ, Stone MJ. Report from the Sixth International Workshop on Waldenström's Macroglobulinemia. Clin Lymphoma Myeloma Leuk 2011;11:69-73.

6. Sekiguchi N, Takezako N, Nagata A, et al. Successful treatment of immunoglobulin D myeloma by bortezomib and dexamethasone therapy. Intern Med 2011;50:2653-7.

7. Owen RG, Treon SP, Al-Katib A, et al. Clinicopathological definition of Waldenstrom's macroglobulinemia: consensus panel recommendations from the Second International Workshop on Waldenstrom's Macroglobulinemia. Semin Oncol 2003;30:110-5.

8. Sekiguchi N, Nomoto J, Nagata A, et al. Gene expression profile signature of aggressive Waldenström macroglobulinemia with chromosome 6q deletion. Biomed Res Int 2018;2018:6728128.

9. Treon SP, Xu L, Yang G, et al. MYD88 L265P somatic mutation in Waldenström's macroglobulinemia. N Engl J Med 2012;367: 826-33.

10. Cao X, Medeiros LJ, Xia Y, et al. Clinicopathologic features and outcomes of lymphoplasmacytic lymphoma patients with monoclonal IgG or IgA paraprotein expression. Leuk Lymphoma 2016;
57:1104-13.

11. King RL, Gonsalves WI, Ansell SM, et al. Lymphoplasmacytic lymphoma with a non-IgM paraprotein shows clinical and pathologic heterogeneity and may harbor MYD88 L265P mutations. Am J Clin Pathol 2016;145:843-51.

12. Varettoni M, Boveri E, Zibellini S, et al. Lymphoplasmacytic lymphoma not associated with an IgM monoclonal paraprotein has distinctive clinical and biological features and a similar outcome as compared with Waldenstrom's macroglobulinemia: multicentric study of the rete ematologica lombarda. Blood (ASH Annual Meeting Abstracts) 2017;130(Suppl):4045.

13. Itchaki G, Dubeau T, Keezer A, et al. Non-IgM secreting lymphoplasmacytic lymphoma - experience of a reference center for waldenstrom macroglobulinemia. Blood (ASH Annual Meeting Abstracts) 2018;132(Suppl):2886.

14. Olszewski AJ, Treon SP, Castillo JJ. Application and outcomes of bendamustine- or bortezomib-based therapy for waldenstrom's macroglobulinemia. Blood (ASH Annual Meeting Abstracts) 2017;130(Suppl):348.

15. Sekiguchi N, Hamano A, Kitagawa T, Ito K, Hirano K, Yamada $\mathrm{K}$. What is the most appropriate regimen for untreated Waldenström macroglobulinemia? - An updated analysis of rituximab and half-dose CHOP therapy and cost effectiveness. Blood Res 2019;54:153-6.

16. Castillo JJ, Gustine JN, Meid K, et al. Response and survival for primary therapy combination regimens and maintenance rituximab in Waldenström macroglobulinaemia. Br J Haematol 2018; 181:77-85 